\title{
Proliferation and differentiation of spermatogonial stem cells
}

\author{
Dirk G. de Rooij \\ Department of Cell Biology, University Medical Center Utrecht, Utrecht, The Netherlands
}

\begin{abstract}
Spermatogonial stem cells ( $A_{s}$ spermatogonia) are single cells that either renew themselves or produce $A_{p r}$ (paired) spermatogonia predestined to differentiate. In turn, the $A_{p r}$ divide into chains of $\mathrm{A}_{\mathrm{al}}$ (aligned) spermatogonia that also divide. The ratio between self-renewal and differentiation of the stem cells is regulated by glial cell line-derived neurotrophic factor produced by Sertoli cells, while the receptors are expressed in stem cells. $A_{s}, A_{p r}$ and $A_{a l}$ spermatogonia proliferate during part of the epithelial cycle forming many $A_{a l}$ spermatogonia. During epithelial stage VIII, almost all $A_{a l}$ spermatogonia, few $A_{p r}$ and very few $A_{s}$ spermatogonia differentiate into $A 1$ spermatogonia. A number of molecules are involved in this differentiation step including the stem cell factor-c-kit system, the Dazl RNA binding protein, cyclin $\mathrm{D}_{2}$ and retinoic acid. There is no fine regulation of the density of spermatogonial stem cells and consequently, in some areas, many A1 and, in other areas, few A1 spermatogonia are formed. An equal density of spermatocytes is then obtained by the apoptosis of A2, A3 or A4 spermatogonia to remove the surplus cells. The $\mathrm{BCl}-2$ family members $\mathrm{Bax}$ and $\mathrm{BCl}-\mathrm{x}_{\mathrm{L}}$ are involved in this density regulation. Several mechanisms are available to cope with major or minor shortages in germ cell production. After severe cell loss, stem cell renewal is preferred above differentiation and the period of proliferation of $A_{s}, A_{p r}$ and $A_{a l}$ spermatogonia is extended. Minor shortages are dealt with, at least in part, by less apoptosis among A2-A4 spermatogonia.
\end{abstract}

Spermatogonial stem cells are the only stem cells in the body that can be recognized and studied at the cellular level with respect to proliferation and differentiation, and the regulation of these activities. However, the complexity of the seminiferous epithelium makes it difficult to study molecular aspects of the regulation of spermatogonial stem cell behaviour. Many cell types are present, complicating the purification of spermatogonial stem cells and it is only recently that a functional test for spermatogonial stem cells has become available (Brinster and Avarbock, 1994; Brinster and Zimmermann, 1994). However, many transgenic mice have been produced, a number of which are infertile and appear to have problems related to spermatogonia. These mice provide the first clues to the molecular aspects of the regulatory mechanisms involved in spermatogonial multiplication and stem cell renewal.

In this review, the available data on the cellular and molecular regulation of spermatogonial multiplication and stem cell renewal will be combined and discussed. Most of the data have been generated in rodent models, and this review will be restricted to results obtained in these animals.

Email: d.g.derooij@med.uu.nl

\section{Spermatogonial multiplication and stem cell renewal}

Spermatogonial multiplication and stem cell renewal can best be studied in whole mounts of seminiferous tubules, as in this way the topographical arrangement of the cells is preserved (Clermont and Bustos-Obregon, 1968). In nonprimate mammals, $\mathrm{A}$-single $\left(\mathrm{A}_{\mathrm{s}}\right)$ spermatogonia are the stem cells of spermatogenesis (Huckins, 1971a; Oakberg, 1971; Lok et al., 1982; de Rooij, 1998). $A_{s}$ spermatogonia are single cells that upon mitosis can divide into two new stem cells. A-paired $\left(A_{p r}\right)$ spermatogonia produce daughter cells that remain connected by an intercellular bridge (Figs 1 and 2 ). The $A_{p r}$ spermatogonia are predestined to develop further along the spermatogenic line and to divide into chains of four $A$-aligned $\left(A_{a l}\right)$ spermatogonia. The chains of $A_{a l}$ spermatogonia can divide further into chains of 8,16 and, rarely, 32 cells (Fig. 2).

Spermatogenesis is a cyclic process that, in mice, can be divided into 12 stages (I-XII). In stage VIII, $A_{s^{\prime}} A_{p r}$ and a few $A_{a l}$ spermatogonia are present. From stage $X$ onwards, these cells start to proliferate in such a way that the numbers of $A_{s}$ and $A_{p r}$ spermatogonia remain relatively constant and more and more $\mathrm{A}_{\mathrm{al}}$ spermatogonia are formed. At about stages II-III (stage XII is followed by stage I), proliferation stops and the cells become arrested in G1-G0 phase. Subsequently, in stages VII-VIII, without division, nearly all $\mathrm{A}_{\mathrm{al}}$ spermatogonia formed during the period of active proliferation differentiate into A1 

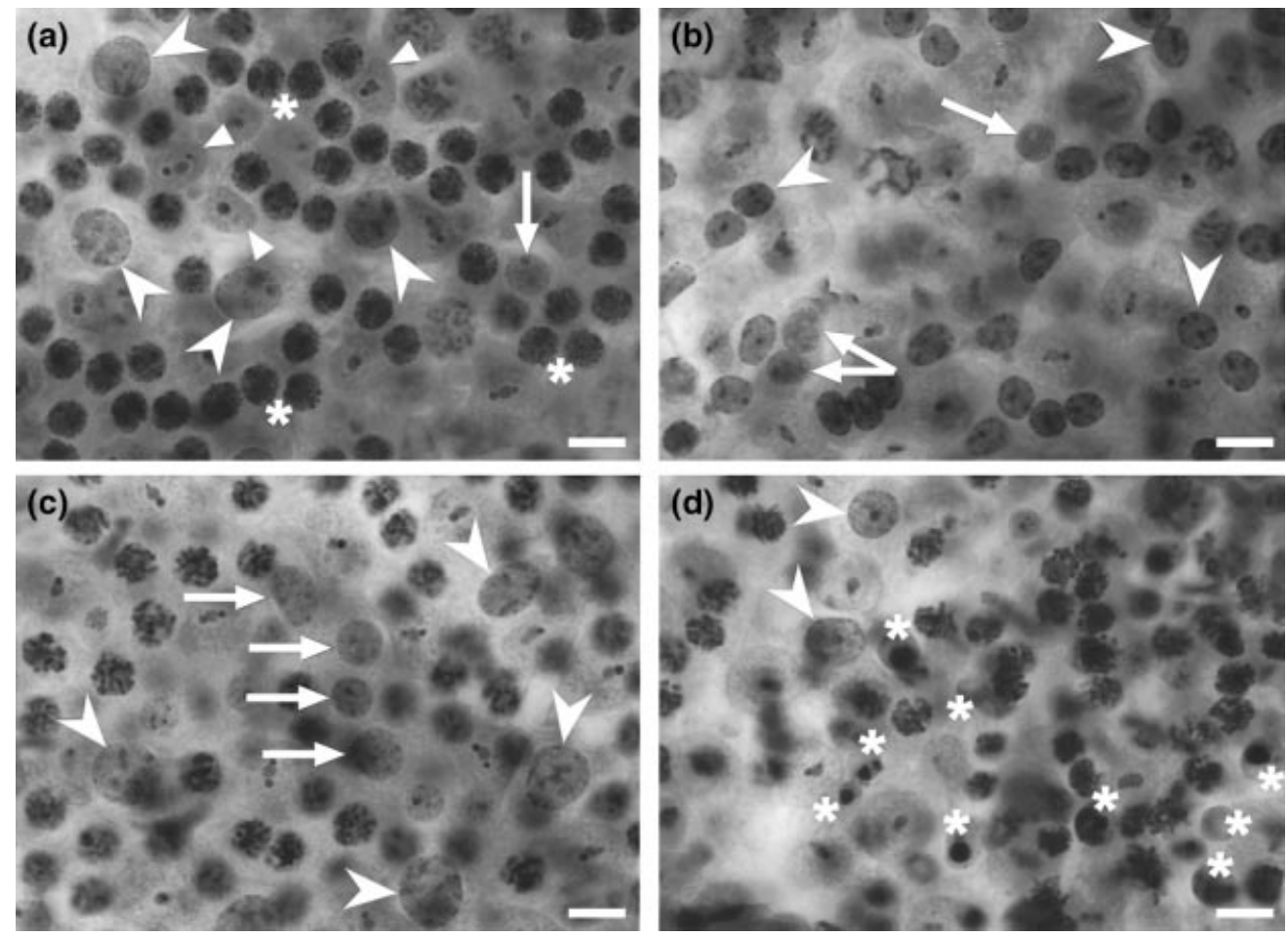

Fig. 1. Spermatogonial cell types on the basal membrane of mouse seminiferous tubules. Only the nuclei of the cells can be seen as the tubules are stained only with haematoxylin. Spermatogonial stem cells, paired $\left(A_{p r}\right)$ or aligned $\left(A_{a l}\right)$ spermatogonia and the other types of spermatogonia can be distinguished from each other in whole mounts of seminiferous tubules by studying the topographical arrangement of the cells on the tubular basal membrane, in combination with the stage of the cycle of the seminiferous epithelium. (a) Area in stage VIII of the epithelial cycle showing A1 spermatogonia just before division into A2 spermatogonia (arrowheads) and an $A_{s}$ spermatogonium (arrow), which is clearly out of phase with the A1 spermatogonia surrounding it. In addition, some of the leptotene spermatocytes (asterisks) and Sertoli cells (triangles) are indicated. (b) Area in stage $\mathrm{V}$ in which $\mathrm{B}$ spermatogonia (some indicated by arrowheads), an $A_{s}$ spermatogonium (single arrow) and $A_{p r}$ spermatogonia (double arrows) are present. (c) Area in stage I showing A3 spermatogonia (arrowheads) just before division into A4 spermatogonia and a chain of four $A_{a l}$ spermatogonia (arrows). (d) Area in stage XII in which some A3 spermatogonia (arrowheads) and a large clone of apoptotic spermatogonia (most of which are indicated by asterisks) are present. Scale bars represent $10 \mu \mathrm{m}$.

spermatogonia. The A1 spermatogonia enter S phase and, in stage IX, divide into A2 spermatogonia, after which there are five subsequent divisions into A3, A4, In and B spermatogonia and primary spermatocytes, respectively. In total, there are 9-11 mitotic divisions during spermatogonial development.

\section{Symmetrical or asymmetrical stem cell divisions?}

So far in this review it has been assumed that spermatogonial stem cell divisions are symmetrical, with divisions either producing two new stem cells or two interconnected cells destined to differentiate $\left(A_{p r}\right)$. Another possibility is that stem cells divide asymmetrically into a stem cell and a cell destined to produce $A_{p r}$ spermatogonia and, therefore, not all $A_{s}$ spermatogonia are true stem cells (Fig. 3). Only a few studies into this possibility have been carried out. In rats, some $A_{s}$ spermatogonia were found to retain incorporated ${ }^{3}[\mathrm{H}]$ thymidine for a very long time, indicating that these cells had a very long cycle while other $A_{s}$ spermatogonia lost their label more quickly. It was proposed that there are long-cyclic true stem cells and short-cyclic $A_{s}$ spermatogonia destined to become $A_{p r}$ spermatogonia (Huckins, 1971b). However, a similar but more detailed study in Chinese hamsters failed to reveal a special category of long-cyclic stem cells (Lok et al., 1984). Although no definite answer can be given as yet to the question of whether stem cell divisions are symmetrical or asymmetrical, in this review, the simpler scheme in which stem cells divide symmetrically is used.

\section{Differentiation steps in spermatogonial development}

Two differentiation steps seem to take place in the developmental path of spermatogonia. First, there is the step from 


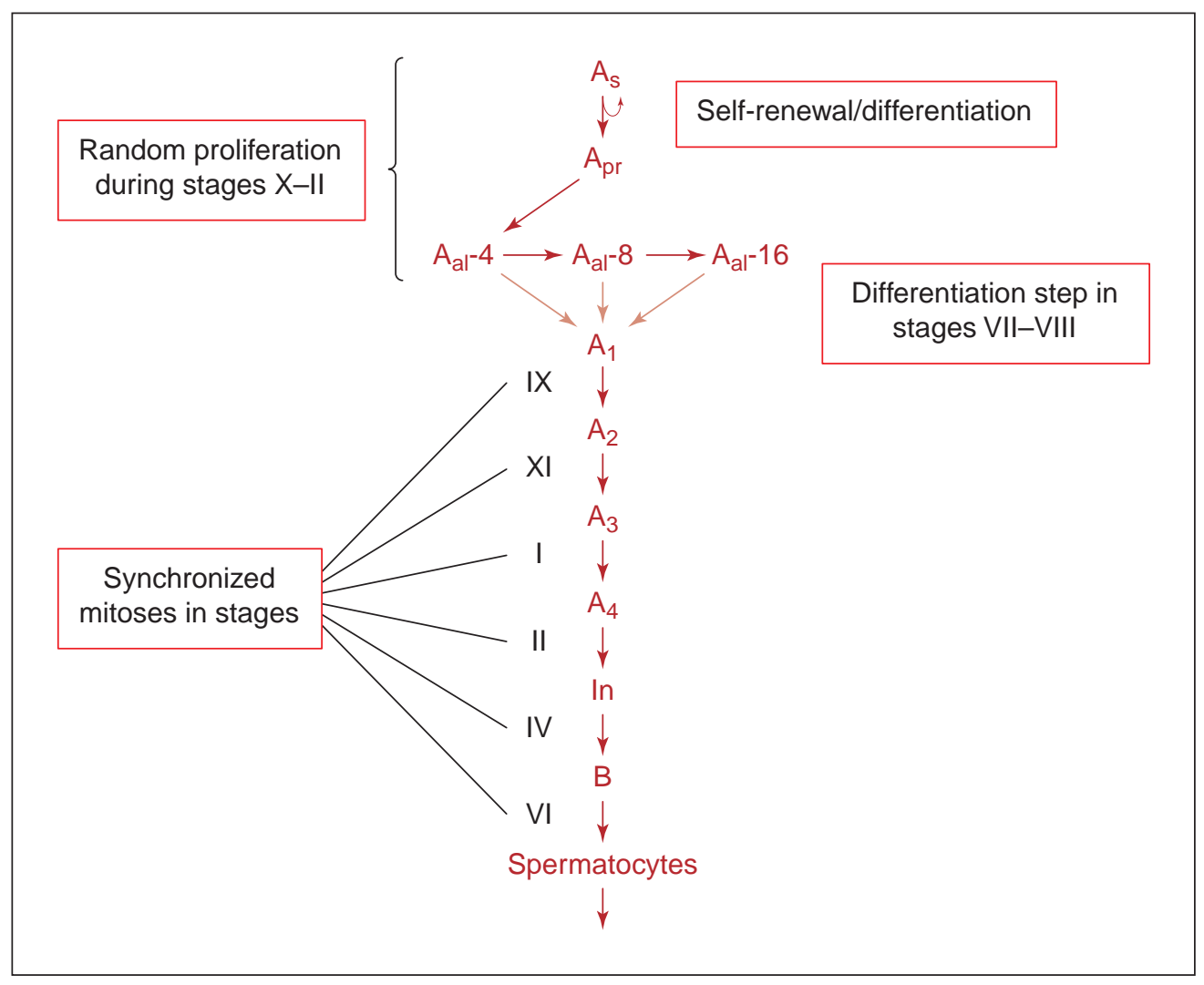

Fig. 2. Scheme of spermatogonial multiplication and stem cell renewal in mice, showing the subsequent spermatogonial cell types and some cell kinetic characteristics of these cells. The scheme starts with the spermatogonial stem cells, the $\mathrm{A}_{\mathrm{s}}$ spermatogonia, that can either renew themselves or give rise to $A_{p r}$ (paired) spermatogonia, which are destined to proceed through the spermatogenic lineage. $A_{a l}$ : aligned spermatogonia. After a series of 9-11 divisions (red arrows), spermatocytes are formed. The pink arrows indicate a differentiation step not involving a division.

the $A_{s}$ spermatogonia to the $A_{p r}$ spermatogonia. From then on, the germ cells consist of clones of interconnected cells of increasing size, as from $\mathrm{A}_{\mathrm{pr}}$ onwards all divisions are such that the daughter cells remain connected by bridges. Nevertheless, it is not known whether the intercellular bridges between $A_{p r}$ and $A_{a l}$ spermatogonia constitute an irreversible differentiation step as no other specific characteristics of these cells are known. In the normal seminiferous epithelium of mice (Tegelenbosch and de Rooij, 1993) and Chinese hamsters (Lok et al., 1982), only clones of 4, 8, 16 or $32 \mathrm{~A}_{\mathrm{al}}$ spermatogonia were found. In the normal situation, the integrity of the intercellular bridges appears to be conserved and the clones do not break up into smaller units. However, in situations in which spermatogenesis is damaged and the only germ cells on the tubular basal membrane are $A_{s}, A_{p r}$ and $A_{a l}$ spermatogonia, as occurs after irradiation (van Beek et al., 1984), in some mutant mice and in cryptorchid mice (de Rooij et al., 1999), odd clones consisting of intermediate numbers of cells, for example 3, 5 or 11 cells, are common. It is not known whether single cells pinched off from pairs or chains are in any way different from the real $A_{S}$ spermatogonia, that is, whether $A_{p r}$ and $A_{a l}$ spermatogonia have already been through an irreversible differentiation step preventing stem cell behaviour. It is possible that the breaking up of clones represents an emergency way to increase the number of stem cells.

The second differentiation step is that from $A_{a}$ to $A 1$ spermatogonia, and this step brings about a marked change in cell behaviour. The duration of the cell cycle becomes shorter from 56 to $42 \mathrm{~h}$ in rats (Huckins, 1971c,d) and from 87 to $60 \mathrm{~h}$ in Chinese hamsters (Lok and de Rooij, 1983; Lok et al., 1983), and the pattern of proliferation changes. The $A_{s}, A_{p r}$ and $A_{a l}$ spermatogonia proliferate at random during a particular period while the clones of A1-B spermatogonia are highly synchronized, dividing during particular epithelial stages, for example, A1 spermatogonia in stage IX and B spermatogonia in stage VI (Fig. 2). In general, when A1-B spermatogonia are unable to divide at the appropriate time, they enter apoptosis. 


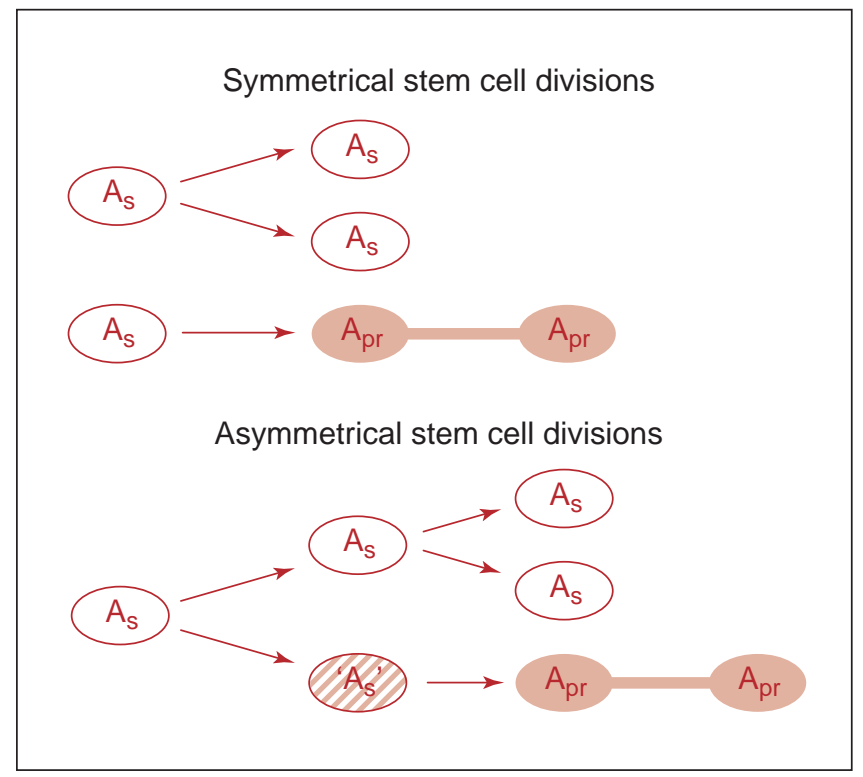

Fig. 3. Two possible mechanisms for spermatogonial stem cell renewal and commitment towards differentiation, that is, the formation of $A_{p r}$ (paired) spermatogonia, are shown. The $A_{p r}$ spermatogonia are shaded to indicate their destination towards differentiation. When stem cell divisions are asymmetrical, there is a special category of $A_{S}$ spermatogonia that are destined to produce $A_{p r}$ spermatogonia. This situation is indicated with stripes.

\section{Regulation of self-renewal and differentiation of spermatogonial stem cells}

In normal seminiferous epithelium, the ratio between selfrenewal and differentiation of spermatogonial stem cells should be about 1.0. More self-renewal than differentiation would reduce the seminiferous epithelium to only stem cells and a tumour might form. If differentiation prevailed, the stem cells would deplete themselves, leading to seminiferous tubules with only the supporting Sertoli cells. Nevertheless, the seminiferous epithelium should be able to cope with cell loss caused, for example, by toxic substances or irradiation. Indeed, an extensive capacity of the epithelium to recover from severe cell loss has been described (van Keulen and de Rooij, 1974, 1975; van den Aardweg et al., 1982, 1983). After irradiation or administration of a cytostatic drug, for example busulfan, spermatogonia and many stem cells are killed and disappear from the epithelium by apoptosis. Subsequently, as spermatocytes are no longer formed, the seminiferous epithelium becomes depleted. When the dose of irradiation or of the drug is not too high, some spermatogonial stem cells survive and start to repopulate the seminiferous epithelium by forming a repopulating colony that grows along the length of the tubules. The growth of the repopulating colonies implies that during repopulation, stem cell renewal is favoured above differentiation. Only stem cells, that is, $A_{s}$ spermatogonia are able to colonize empty stretches of seminiferous tubules and establish full spermatogenesis. Indeed, Van Beek et al. (1990) studied the composition of early repopulating colonies and showed that during the first six divisions after irradiation the stem cells virtually only selfrenew. This finding implies that there must be a regulatory mechanism controlling the ratio between self-renewal and differentiation of spermatogonial stem cells.

Data from studies investigating how stem cell renewal and differentiation ( $A_{p r}$ formation) are regulated at the molecular level have now become available (Meng et al., 2000). In 3-week-old mice overexpressing glial cell linederived neurotrophic factor (GDNF), clusters of mostly single A spermatogonia are present. At later ages, the clusters disappear but the tubules become lined with the single A spermatogonia that displace the remnants of normal spermatogenesis still present at 3 weeks. At the age of 1 year, germ cell tumours were found in these mice. As the only single germ cells that are present in the testis are spermatogonial stem cells $\left(A_{s}\right)$, these data indicate that GDNF, which is produced by Sertoli cells, promotes stem cell renewal. In line with this finding, seminiferous tubules without germ cells or in which generations of germ cells are missing are present in the heterozygote knock outs for GDNF (GDNF+/-), indicating that stem cell depletion is taking place in these mice. In addition, the receptors for GDNF, Ret and GFR $\alpha 1$ are expressed in the cluster cells in GDNF-overexpressing mice, indicating that, by producing more or less GDNF, Sertoli cells can regulate the number of spermatogonial stem cells.

\section{Period of proliferation of the $A_{s}, A_{p r}$ and $A_{a l}$ spermatogonia}

As described above, during the normal cycle of the seminiferous epithelium there is active proliferation of $A_{s^{\prime}}$ $A_{p r}$ and $A_{a l}$ spermatogonia during stages $X-I I I$, and little or no proliferation in the remaining stages. However, when the numbers of $\mathrm{A} 4$, In and $\mathrm{B}$ spermatogonia are low, the proliferation period is extended to stage VII (van Keulen and de Rooij, 1974; de Rooij et al., 1985). There appears to be a feedback mechanism between A4, In and B spermatogonia and the $A_{s}, A_{p r}$ and $A_{a l}$ spermatogonia lying in between these cells. When the numbers of A4-B spermatogonia are about $50 \%$ lower than in the normal testis, the proliferative activity of the $A_{s}, A_{p r}$ and $A_{a l}$ spermatogonia continues beyond stage II (van Keulen and de Rooij, 1974). At present, it is not known whether this feedback regulatory mechanism is direct, from one type of spermatogonia to the other, or indirect via Sertoli cells. Neither is it known what kind of factors play a role in inhibiting or stimulating the proliferative activity of the $A_{s}, A_{p r}$ and $A_{a l}$ spermatogonia, although the presence of a chalone-like, proliferationinhibiting factor has been suggested (Clermont and Mauger, 1976; de Rooij, 1980; Bustos-Obregon, 1989). 


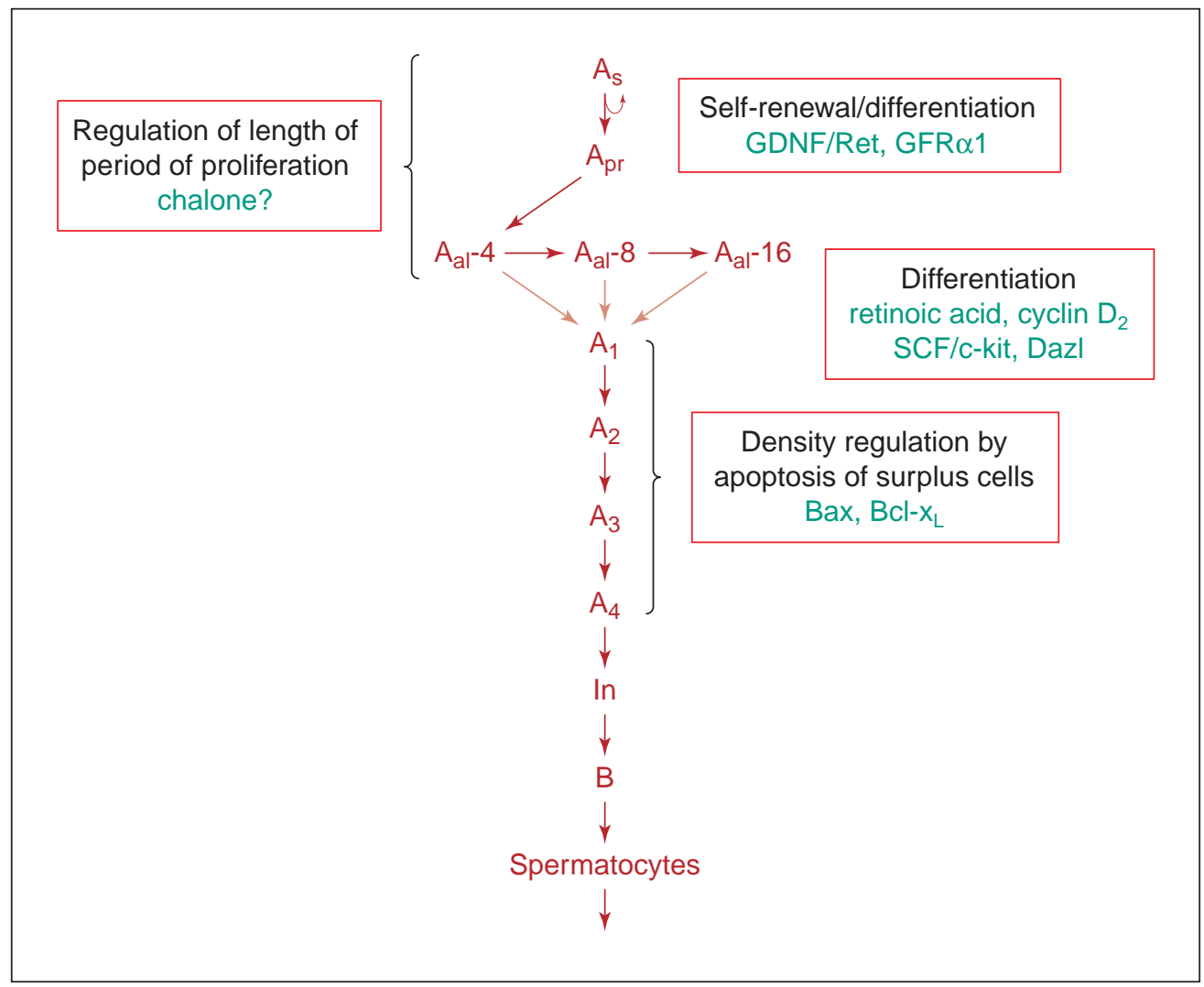

Fig. 4. Scheme for spermatogonial multiplication and stem cell renewal in the mouse, in which the function of various factors in the regulation of spermatogonial multiplication and stem cell renewal is indicated. $\mathrm{A}_{\mathrm{s}}$ : spermatogonial stem cells; $\mathrm{A}_{\mathrm{pr}}$ : paired spermatogonia; $\mathrm{A}_{\mathrm{al}}$ : aligned spermatogonia; Dazl: deleted in azoospermia-like gene; GDNF: glial cell line-derived neurotrophic factor; GFR $\alpha 1$ : glial cell line-derived neurotrophic factor receptor $\alpha 1$; SCF: stem cell factor.

\section{Regulation of the differentiation of $A_{a l}$ into $A 1$ spermatogonia}

During each cycle of the seminiferous epithelium, the proliferative activity of $A_{s}, A_{p r}$ and $A_{a l}$ spermatogonia produces a new cohort of $A_{a l}$ spermatogonia. This cohort of $\mathrm{A}_{\mathrm{al}}$ spermatogonia is largely quiescent from stage III onwards and, at some time during stages III-VIII, probably during stages VII-VIII (Schrans-Stassen et al., 1999), these cells differentiate into A1 spermatogonia. The A1 spermatogonia all enter $\mathrm{S}$ phase in stage VIII and divide into A2 spermatogonia in stage IX. The differentiation of the $A_{a l}$ spermatogonia does not seem to depend on a preceding mitotic arrest. As discussed above, the proliferation period of the $A_{s}, A_{p r}$ and $A_{a l}$ spermatogonia is prolonged until about stage VII when there are only a few A4, In and $B$ spermatogonia present and this does not seem to prevent the formation of A1 spermatogonia (van Keulen and de Rooij, 1974). The opposite, a prolonged period of mitotic arrest, takes place in vitamin A-deficient mice and rats in which the differentiation of $A_{a l}$ spermatogonia is inhibited (van Pelt and de Rooij, 1990a,b; van Pelt et al., 1995). Despite a very long period of arrest, upon administration of vitamin A or retinoic acid to vitamin A-deficient animals, there is a massive differentiation of $A_{a l}$ into $A 1$ spermatogonia.

Clearly, the overwhelming majority of the A1 spermatogonia formed during each epithelial cycle derives from $A_{\text {al }}$ spermatogonia. However, it is possible that sometimes $A_{p r}$ and even $A_{s}$ also differentiate into A1 spermatogonia. Results from cell counts of spermatogonia throughout the epithelial cycle in mice indicated that during each epithelial cycle some $A_{p r}$ spermatogonia also become A1 spermatogonia (Tegelenbosch and de Rooij, 1993). Furthermore, in rams, in which the A1 spermatogonia have a very characteristic morphology, pairs and exceptionally single A1 spermatogonia were occasionally observed, indicating that these cells were derived from $A_{p r}$ and $A_{s}$ spermatogonia, respectively (Lok et al., 1982). On the other hand, some clones of $A_{a l}$ spermatogonia (chains of four and occasionally eight) that apparently have escaped from differentiation into A1 spermatogonia, are found in stage IX (de Rooij, 1973; Lok et al., 1982).

Results of studies on the molecules involved in differentiation into A1 spermatogonia have been reported by de Rooij and Grootegoed (1998) and de Rooij et al. 
(2000). It has been established that retinoic acid is involved in differentiation into A1 spermatogonia as, in cases of vitamin $A$ deficiency, the $A_{a l}$ spermatogonia are unable to differentiate and remain quiescent (van Pelt and de Rooij, 1990a,b; van Pelt et al., 1995). It is not yet known whether the action of retinoic acid in inducing differentiation is direct, or indirect via Sertoli cells. Both spermatogonia and Sertoli cells possess nuclear receptors for retinoids (Akmal et al., 1997; Gaemers et al., 1998; Cupp et al., 1999). The stem cell factor (SCF)-c-kit receptor system is also involved in differentiation into A 1 spermatogonia. Mutations in the $C$ kit and the SCF genes have a variable effect on spermatogenesis, indicating that this system has a role at various steps in the spermatogenic lineage. One mutant, the $S / 17 H / S / 17 H$ mouse, appears to have an arrest precisely at the differentiation step of $A_{a l}$ into $A 1$ spermatogonia (de Rooij et al., 1999), indicating that the action of the SCF-Ckit system is essential at this step. In accordance with this finding, from about stage $\mathrm{VI}$ onwards, the $\mathrm{A}_{\mathrm{al}}$ spermatogonia start to become immunohistochemically positive for c-kit (Schrans-Stassen et al., 1999). In mice deficient in the RNA binding protein encoded by the Dazl (deleted in azoospermia-like) gene (Cooke, 1999), the differentiation of $\mathrm{A}_{\mathrm{al}}$ spermatogonia into A1 also does not take place (B. H. G. J. Schrans-Stassen, P. T. K. Saunders, H. J. Cooke, D. G. de Rooij, unpublished). The Dazl protein is expressed in spermatogonia (Ruggiu et al., 1997), indicating that it is also essential in spermatogonial differentiation. Finally, a study of the expression of cyclins $D$ in various situations revealed that, in spermatogonia, cyclin $D_{2}$ is only expressed around epithelial stage VIII when the $A_{a l}$ differentiate into $A 1$ (Beumer et al. 2000a). In the remaining $A_{s^{\prime}} A_{p r}$ and $A_{a l}$ spermatogonia in the testis, cyclin $D_{2}$ is not expressed. Cyclin $D_{2}$ is also induced when the $A_{a l}$ spermatogonia present in the vitamin A-deficient testis are induced to differentiate into A1 spermatogonia. Furthermore, cyclin $\mathrm{D}_{2}$ expression is found at the start of spermatogenesis when the gonocytes produce A1 spermatogonia. Taken together, these data strongly indicate a role for cyclin $D_{2}$ in the differentiation of $\mathrm{A}_{\mathrm{al}}$ into $\mathrm{A} 1$ spermatogonia (Beumer et al., 2000a).

There are several other situations in which the differentiation of $A_{a l}$ spermatogonia becomes arrested, for example, in cryptorchid (de Rooij et al., 1999) and juvenile spermatogonial depletion (jsd) mutant mice (de Rooij et al., 1999), in irradiated rats (Shuttlesworth et al., 2000) and probably also in 3,5-hexanedione-treated rats (Boekelheide and Hall, 1991). In none of these cases are the specific molecules that no longer function in spermatogonial differentiation known. However, in jsd/jsd mice, and irradiated and hexanedione-treated rats, spermatogonial differentiation can be enhanced again by decreasing testosterone concentrations (Blanchard et al., 1998; Meistrich, 1998; Matsumiya et al., 1999; Shuttlesworth et al., 2000). As Sertoli cells have receptors for testosterone and spermatogonia do not, it is possible that Sertoli cell function is failing in the above cases.

\section{Regulation of cell density in spermatogenesis}

The cell density of newly formed spermatocytes in different stretches of seminiferous tubules appears to be virtually the same everywhere (de Rooij and Lok, 1987), indicating that germ cell density is tightly controlled. The density of all types of spermatogonia along stretches of whole mounts of Chinese hamster seminiferous tubules was determined to establish how germ cell density regulation takes place (de Rooij and Janssen, 1987; de Rooij and Lok, 1987). Differences of up to almost fivefold were found in the density of spermatogonial stem cells and up to threefold in the total densities of clones of $A_{s^{\prime}} A_{p r}$ and $A_{a l}$ spermatogonia. As a consequence, the density of the A1 spermatogonia in different stretches of seminiferous tubules differed by a factor of up to 3.7. Nevertheless, the density of the preleptotene spermatocytes varied only by a factor of 1.3 at the most, and further cell counts revealed the density of the In spermatogonia to be even. Hence, density regulation has to take place somewhere in between $\mathrm{A} 1$ and In spermatogonia. As spermatogenesis is rigidly organized, it is inconceivable that extra cell divisions of A1-A4 spermatogonia occur to fill up low density areas. Therefore, it was concluded that in the normal epithelium in all tubular areas, enough, and frequently too many, A1 spermatogonia are formed during each cycle of the seminiferous epithelium. Subsequently, an even germ cell density is achieved by apoptosis of the surplus of A2, A3 and A4 spermatogonia in particular areas (Fig. 1d).

To date, there are no clues as to how a surplus of germ cells is sensed and what triggers the apoptotic mechanism in some of the A2-A4 spermatogonia in a particular area. It is possible that the Sertoli cells somehow regulate the optimal number of spermatogonia or that when the large clones of A2, A3 and A4 spermatogonia get too close to each other, they hinder each other's expansion at division. However, Huckins (1978) did show that the clones of interconnected A2-A4 spermatogonia enter apoptosis as a whole.

Data have become available on the molecular mechanisms of apoptosis induction in surplus spermatogonia. Ectopic or overexpression of the apoptosis-inhibiting proteins Bcl-2 and $\mathrm{BCl}-\mathrm{x}_{\mathrm{L}}$ and deficiency of the apoptosisinducing protein Bax have been shown to cause an accumulation of spermatogonia in the testis, leading ultimately to apoptosis of all cells soon after the start of the meiotic prophase (Knudson et al., 1995; Furuchi et al., 1996; Rodriguez et al., 1997), indicating that the Bcl-2 family of apoptosis-regulating proteins is involved in spermatogonial density regulation. Immunohistochemical studies revealed that $\mathrm{Bcl}-2$ is not expressed in spermatogonia but both Bax and Bcl- $x_{\mathrm{L}}$ were detected in these cells (de Rooij and Grootegoed, 1998; Beumer et al., 2000b) and so are probably involved in regulating germ cell density.

\section{Conclusions}

From present knowledge on the regulation of spermatogonial multiplication and stem cell renewal the 
following picture emerges (Fig. 4). In the normal seminiferous epithelium, spermatogonial stem cells, by way of either symmetrical or asymmetrical divisions, produce new stem cells or $A_{p r}$ spermatogonia that are destined to develop further along the developmental pathway that leads to spermatozoa. Normally, the ratio between renewal and $A_{p r}$ formation will be close to 1.0, to preserve steady-state kinetics. The GDNF-Ret and GFR $\alpha 1$ receptors system seems to play an important role in the regulation of selfrenewal and differentiation of the stem cells. As Sertoli cells produce GDNF, they apparently regulate this aspect of spermatogonial stem cell behaviour.

There is no mechanism that tightly controls spermatogonial stem cell density, since large differences are apparent among different stretches of seminiferous tubules. Consequently, large differences are also found in the density of the differentiating cells produced by the stem cells, for example, A1 spermatogonia, in different stretches of tubules. However, in general, enough or more than enough A1 spermatogonia are produced everywhere and surplus cells are removed by apoptosis of A2-A4 spermatogonia, involving the $\mathrm{BCl}-2$ family of apoptosisregulating proteins.

A specific, early point of differentiation in the spermatogenic lineage takes place in epithelial stages VII-VIII, during which $A_{a l}$ spermatogonia differentiate into A1 spermatogonia. This differentiation step involves the action of retinoic acid, the SCF-c-kit system, cyclin $\mathrm{D}_{2}$ and the Dazl protein and seems to become disturbed by high concentrations of testosterone. Differentiation into A1 spermatogonia generally takes place in $A_{a l}$ spermatogonia but, occasionally, $A_{p r}$ spermatogonia and, rarely, $A_{s}$ spermatogonia may also become A1 spermatogonia. However, during the normal epithelial cycle in mice and Chinese hamsters, a few $A_{a l}$ chains of four and, rarely, a chain of eight escape differentiation. The chance of differentiation into A1 may increase with increasing chain length, and even stem cells may not be excluded from this event.

Although the above mechanism describes the situation in normal epithelium, there are emergency mechanisms as well. First, spermatogonial stem cell renewal becomes strongly preferred above $A_{\text {pr }}$ formation after heavy cell loss, for example, inflicted by irradiation, and this is the basic mechanism by which the seminiferous epithelium can be repopulated. Second, when the number of A4-B spermatogonia is $50 \%$ lower than it is in the normal testis, the proliferative activity of the $A_{s}, A_{p r}$ and $A_{a l}$ spermatogonia does not stop in epithelial stage III but continues up to stage VII, apparently in an effort to increase cell production to a sufficient level. Third, although it seems wasteful that, in most areas, too many A1 spermatogonia are formed, this mechanism does provide a reserve capacity that can be used to cope with light cell loss since, when there are fewer A1 spermatogonia, there will be less apoptosis.

It can be concluded that cell production in the seminiferous epithelium is a very efficiently organized process. An even density of cells is produced constantly as a result of several emergency and fine tuning mechanisms that enable the testis to cope with local or overall problems with cell production. The spermatogonial stem cells are the best known of all the stem cell systems of the body with respect to their morphology and behaviour at the cellular level. The complexity of the seminiferous epithelium has long hindered progress in studies of the molecular biology of the regulation of spermatogonial multiplication and stem cell renewal. However, the availability of new experimental systems and transgenic mice should enable faster progress in this field.

\section{References}

Key references are identified by asterisks.

Akmal KM, Dufour JM and Kim KH (1997) Retinoic acid receptor alpha gene expression in the rat testis: potential role during the prophase of meiosis and in the transition from round to elongating spermatids Biology of Reproduction $\mathbf{5 6}$ 549-556

Beumer TL, Roepers-Gajadien HL, Gademan IS, Kal HB and de Rooij DG (2000a) Involvement of the D-type cyclins in germ cell proliferation and differentiation in the mouse testis Biology of Reproduction 63 1893-1898

Beumer TL, Roepers-Gajadien HL, Gademan IS, Lock TMTW, Kal HB and de Rooij DG (2000b) Apoptosis regulation in the testis: involvement of Bcl-2 family members Molecular Reproduction and Development $\mathbf{5 6}$ 353-359

Blanchard KT, Lee J and Boekelheide K (1998) Leuprolide, a gonadotropinreleasing hormone agonist, re-establishes spermatogenesis after 2,5hexanedione-induced irreversible testicular injury in the rat, resulting in normalized stem cell factor expression Endocrinology 139 236-244

Boekelheide K and Hall SJ (1991) 2,5-hexanedione exposure in the rat results in long-term testicular atrophy despite the presence of residual spermatogonia Journal of Andrology 12 18-26

Brinster RL and Avarbock MR (1994) Germline transmission of donor haplotype following spermatogonial transplantation Proceedings National Academy of Sciences USA $9111303-11307$

Brinster RL and Zimmermann JW (1994) Spermatogenesis following male germ-cell transplantation Proceedings National Academy of Sciences USA $9111298-11302$

Bustos-Obregon E (1989) G1 spermatogonial chalone Archivos de Biologia Y Medicine Experimentale 22 15-23

Clermont Y and Bustos-Obregon E (1968) Re-examination of spermatogonial renewal in the rat by means of seminiferous tubules mounted 'in toto' American Journal of Anatomy 122 237-247

Clermont $\mathrm{Y}$ and Mauger A (1976) Effect of a spermatogonial chalone on the growing rat testis Cell and Tissue Kinetics 9 99-104

Cooke HJ (1999) Y chromosome and male infertility Reviews of Reproduction 4 5-10

Cupp AS, Dufour JM, Kim G, Skinner MK and Kim KH (1999) Action of retinoids on embryonic and early postnatal testis development Endocrinology $1402343-2352$

de Rooij DG (1973) Spermatogonial stem cell renewal in the mouse I. Normal situation Cell and Tissue Kinetics 6 281-287

de Rooij DG (1980) Effect of testicular extracts on proliferation of spermatogonia in the mouse Virchows Archiv B Cell Pathology Including Molecular Pathology 33 67-75

de Rooij DG (1998) Stem cells in the testis International Journal of Experimental Pathology 79 67-80

*de Rooij DG and Grootegoed JA (1998) Spermatogonial stem cells Current Opinion in Cell Biology 10 694-701

de Rooij DG and Janssen JM (1987) Regulation of the density of spermatogonia in the seminiferous epithelium of the Chinese hamster I. Undifferentiated spermatogonia Anatomical Record 217 124-130

de Rooij DG and Lok D (1987) Regulation of the density of spermatogonia 
in the seminiferous epithelium of the Chinese hamster II. Differentiating spermatogonia Anatomical Record 217 131-136

de Rooij DG, Lok D and Weenk D (1985) Feedback regulation of the proliferation of the undifferentiated spermatogonia in the Chinese hamster by the differentiating spermatogonia Cell and Tissue Kinetics 18 71-81

*de Rooij DG, Okabe M and Nishimune M (1999) Arrest of spermatogonial differentiation in $j s d / j s d, S / 17 H / S / 17 H$ and cryptorchid mice Biology of Reproduction 61 842-847

de Rooij DG, Schrans-Stassen BHGJ, van Pelt AMM, Shuttlesworth GA, Meistrich ML, Okabe $\mathbf{M}$ and Nishimune $\mathbf{Y}$ (2000) Regulation of the differentiation of the undifferentiated spermatogonia. In The Testis: From Stem Cell to Sperm Function pp 43-54 Ed. E Goldberg. Springer Verlag, New York

Furuchi T, Masuko K, Nishimune Y, Obinata M and Matsui Y (1996) Inhibition of testicular germ cell apoptosis and differentiation in mice misexpressing Bcl-2 in spermatogonia Development 122 1703-1709

Gaemers IC, van Pelt AM, van der Saag PT, Hoogerbrugge JW, Themmen AP and de Rooij DG (1998) Differential expression pattern of retinoid X receptors in adult murine testicular cells implies varying roles for these receptors in spermatogenesis Biology of Reproduction 58 1351-1356

Huckins C (1971a) The spermatogonial stem cell population in adult rats I. Their morphology, proliferation and maturation Anatomical Record 169 $533-557$

Huckins C (1971b) The spermatogonial stem cell population in adult rats 3. Evidence for a long-cycling population Cell and Tissue Kinetics 4 335-349

Huckins C (1971c) The spermatogonial stem cell population in adult rats II. A radioautographic analysis of their cell cycle properties Cell and Tissue Kinetics 4 313-334

Huckins C (1971d) Cell cycle properties of differentiating spermatogonia in adult Sprague-Dawley rats Cell and Tissue Kinetics 4 139-154

Huckins C (1978) Spermatogonial intercellular bridges in whole-mounted seminiferous tubules from normal and irradiated rodent testes American Journal of Anatomy 153 97-121

Knudson CM, Tung KS, Tourtellotte WG, Brown GA and Korsmeyer SJ (1995) Bax-deficient mice with lymphoid hyperplasia and male germ cell death Science 270 96-99

Lok D and de Rooij DG (1983) Spermatogonial multiplication in the Chinese hamster I. Cell cycle properties and synchronization of differentiating spermatogonia Cell and Tissue Kinetics 16 7-18

Lok D, Weenk D and de Rooij DG (1982) Morphology, proliferation, and differentiation of undifferentiated spermatogonia in the Chinese hamster and the ram Anatomical Record 203 83-99

Lok D, Jansen MT and de Rooij DG (1983) Spermatogonial multiplication in the Chinese hamster II. Cell cycle properties of undifferentiated spermatogonia Cell and Tissue Kinetics 16 19-29

Lok D, Jansen MT and de Rooij DG (1984) Spermatogonial multiplication in the Chinese hamster IV. Search for long cycling stem cells Cell and Tissue Kinetics 17 135-143

Matsumiya K, Meistrich ML, Shetty G, Dohmae K, Tohda A, Okuyama A and Nishimune $\mathbf{Y}$ (1999) Stimulation of spermatogonial differentiation in juvenile spermatogonial depletion (jsd) mutant mice by gonadotropinreleasing hormone antagonist treatment Endocrinology $1404912-4915$
Meistrich ML (1998) Hormonal stimulation of the recovery of spermatogenesis following chemo- or radiotherapy Apmis 106 37-45

*Meng X, Lindahl M, Hyvonen ME et al. (2000) Regulation of cell fate decision of undifferentiated spermatogonia by GDNF Science $\mathbf{2 8 7}$ 1489-1493

Oakberg EF (1971) Spermatogonial stem-cell renewal in the mouse Anatomical Record 169 515-531

Rodriguez I, Ody C, Araki K, Garcia I and Vassalli P (1997) An early and massive wave of germinal cell apoptosis is required for the development of functional spermatogenesis EMBO Journal 16 2262-2270

Ruggiu M, Speed R, Taggart M, McKay SJ, Kilanowski F, Saunders P, Dorin J and Cooke HJ (1997) The mouse Dazla gene encodes a cytoplasmic protein essential for gametogenesis Nature 389 73-77

*Schrans-Stassen BHGJ, van de Kant HJG, de Rooij DG and van Pelt AMM (1999) Differential expression of c-kit in mouse undifferentiated and differentiating type A spermatogonia Endocrinology 140 5894-5900

Shuttlesworth GA, de Rooij DG, Huhtaniemi I, Reissmann T, Russell LD, Shetty G, Wilson G and Meistrich ML (2000) Enhancement of A spermatogonial proliferation and differentiation in irradiated rats by GnRH antagonist administration Endocrinology 141 37-49

Tegelenbosch RA and de Rooij DG (1993) A quantitative study of spermatogonial multiplication and stem cell renewal in the $\mathrm{C} 3 \mathrm{H} / 101 \mathrm{~F} 1$ hybrid mouse Mutation Research 290 193-200

van Beek MEAB, Davids JAG, van de Kant HJG and de Rooij DG (1984 Response to fission neutron irradiation of spermatogonial stem cells in different stages of the cycle of the seminiferous epithelium Radiation Research 97 556-569

*van Beek MEAB, Meistrich ML and de Rooij DG (1990) Probability of selfrenewing divisions of spermatogonial stem cells in colonies, formed after fission neutron irradiation Cell and Tissue Kinetics 23 1-16

van den Aardweg GJ, de Ruiter-Bootsma AL, Kramer MF and Davids JA (1982) Growth of spermatogenetic colonies in the mouse testis after irradiation with fission neutrons Radiation Research 89 150-165

van den Aardweg GJ, de Ruiter-Bootsma AL, Kramer MF and Davids JA (1983) Growth and differentiation of spermatogenetic colonies in the mouse testis after irradiation with fission neutrons Radiation Research 94 447-463

van Keulen CJ and de Rooij DG (1974) The recovery from various gradations of cell loss in the mouse seminiferous epithelium and its implications for the spermatogonial stem cell renewal theory Cell and Tissue Kinetics 7 549-558

van Keulen CJ and de Rooij DG (1975) Spermatogenetic clones developing from repopulating stem cells surviving a high dose of an alkylating agent Cell and Tissue Kinetics 8 543-551

van Pelt AMM and de Rooij DG (1990a) The origin of the synchronization of the seminiferous epithelium in vitamin A-deficient rats after vitamin A replacement Biology of Reproduction 42 677-682

van Pelt AMM and de Rooij DG (1990b) Synchronization of the seminiferous epithelium after vitamin A replacement in vitamin Adeficient mice Biology of Reproduction 43 363-367

van Pelt AMM, van Dissel-Emiliani FMF, Gaemers IC, van der Burg MJ, Tanke HJ and de Rooij DG (1995) Characteristics of A spermatogonia and preleptotene spermatocytes in the vitamin A-deficient rat testis Biology of Reproduction 53 570-578 